\title{
Two new skink-endoparasitic species of Meteterakis (Nematoda, Heterakidae, Meteterakinae) from East Asian islands
}

\author{
Naoya Sata ${ }^{1}$ \\ 1 Department of Zoology, Graduate School of Science, Kyoto University, Sakyo, Kyoto 606-8502, Japan \\ http://zoobank.org/2922776D-5C7B-4444-AEA3-6BAC0FDC6F57 \\ Corresponding author: Naoya Sata (sata@zoo.zool.kyoto-u.ac.jp)
}

\begin{abstract}
Received 30 May 2018

Accepted 29 June 2018

Published 6 July 2018

Academic editor:

Andreas Schmidt-Rhaesa

\section{Key Words}

Ascaridida

Meteterakis

new species

Plestiodon chinensis

Plestiodon japonicus

Japan

Here, two new nematodes of Meteterakis Karve, 1930 from Taiwan and the western Japanese Archipelago that are endoparasitic to scincid lizards are described. The Taiwanese Meteterakis formosensis $\mathbf{s p .}$ n. and the Japanese Meteterakis occidentalis sp. n. can be distinguished from other congeners by the following characteristics: spicules 437-537 $\mu \mathrm{m}$ in length in $M$. formosensis sp. n. and 359-538 $\mu \mathrm{m}$ in M. occidentalis sp. n.; spicules with narrow alae, funnel-shaped, proximal ends ventrally bent; prevulval flap well-developed; gubernaculum mass absent; preclocal sucker with diameter of 35-47 $\mu \mathrm{m}$ in $M$. formosensis sp. n. and of 32-36 $\mu \mathrm{m}$ in M. occidentalis sp. n.; 9-15 caudal papillae on both lateral sides in M. formosensis sp. n. and 10-14 in M. occidentalis sp. n.; and relatively narrow lateral alae, ending at region near proximal end of spicule in male or at region anterior to anus in female. Meteterakis formosensis sp. n. is distinguished from $M$. occidentalis sp. n. by possessing spicules with hyaline pointed distal ends and well-developed cuticular backing structures. The present study suggests that lateral alae can be used as diagnostic character among the Meteterakis species, and it revealed that meteterakine nematodes mature in the host's small intestine and then migrate to the rectum to oviposit.
\end{abstract}

Taiwan

\section{Introduction}

Meteterakis Karve, 1930 is a parasitic nematode genus, which is specific to amphibians (frogs and caecilians) and reptiles (lizards and land turtles) (Baker 1984, 1987, Hasegawa and Asakawa 2004, Zhang and Zhang 2011, Junker et al. 2015), and currently consists of 27 species. They are distributed in South, Southeast and East Asian regions, as well as in Oceania and Sao Tome Island, which is in the Gulf of Guinea (Baker 1984, 1987, Junker et al. 2015). Four species of Meteterakis have been recorded from the East Asian islands, which consist of the islands from the Japanese Archipelago to Taiwan: M. japonica (Wilkie, 1930), inhabiting the eastern Japanese Archipelago and Shimokoshikijima Island, an islet west off Kyushu, western Japan; M. amamiensis Hasegawa, 1990, indigenous to the western Japanese Archipelago and northern the Ryukyu Archipelago (Kodakarajima and Amamioshima
Islands); M. ishikawanae Hasegawa, 1987, described from the Okinawan Islands; and the Burmese M. govindi Karve, 1930 , which is the type species of the genus, from southern Taiwan (Karve 1930, Wilkie 1930, Yamaguti 1935, 1941, Hasegawa 1987, 1990, 1992, Telford Jr 1997, Goldberg and Bursey 2002, Bursey et al. 2005, Norval et al. 2014, Sata 2015, 2018). Although M. japonica was once reported from Miyakojima Island in the southern Ryukyu Archipelago (Hasegawa 1984), the individuals from the islet can be distinguished from the "true" M. japonica by the absence of a gubernaculum (M. japonica possesses a gubernaculum; Wilkie 1930, Inglis 1958).

A molecular phylogenetic study revealed that the EastAsian insular Meteterakis nematodes are divided into two major clades (Sata 2018). One phylogroup contains $M$. japonica and $M$. ishikawanae, while the other major clade contains $M$. amamiensis and three distinct unidentified nematodes from Ishigakijima and Iriomotejima islands in 
the southern Ryukyu Archipelago and Taiwan. The study also highlights the deep-genetic divergence between the M. amamiensis populations inhabiting Kodakarajima and Amamioshima (type locality) Islands and those distributed in the western Japanese Archipelago (Sata 2018).

Clarifying the systematic accounts of the aforementioned unidentified species will lead to a better understanding of the species diversity and evolutionary history of Meteterakis parasites inhabiting the East Asian islands. In the present study, therefore, the taxonomic states of the unidentified Taiwanese species and the M. amamiensis populations in the western Japanese Archipelago are investigated, and each is described as a new species.

\section{Methods}

The Meteterakis specimens examined in this study were obtained from the scincid lizard hosts, Plestiodon chinensis (Gray, 1838) and Plestiodon japonicus (Peters, 1864), which were collected from Taiwan and the western Japanese Archipelago (Fig. 1), respectively. The host lizard specimens were identified based on Okamoto and Hikida (2012) and Kurita et al. (2017). Hosts were collected and handled in accordance with the Regulations of Animal Experimentations at Kyoto University (approval numbers: H24014 and H2711). All captured lizards were euthanized by an injection of sodium pentobarbital. The body cavity of each specimen was dissected by a longitudinal incision, and then the digestive tract was removed. The excised organs were dissected longitudinally, and the lumens were investigated. The obtained nematode individuals were fixed with a hot $5 \%$ solution of glycerin in $70 \%$ ethyl alcohol. To clear the nematode specimens, they were placed in $50 \%$ solution of glycerin in $70 \%$ ethyl alcohol, then incubated 2-3 days at $60{ }^{\circ} \mathrm{C}$ to gradually evaporate the ethyl alcohol. The cleared specimens were observed with a light microscope (OLYMPUS BX53). The measurements in males were given for a holotype, followed by the range of paratypes in parentheses; for females, averages were provided, followed by the range of the paratypes in parentheses. All measurements were described in micrometers $(\mu \mathrm{m})$ unless otherwise stated. Both the nematode and reptile specimens examined in this study have been deposited in the Zoological Collection of Kyoto University (KUZ).

For comparison, the following Meteterakis specimens deposited in the KUZ collection were examined: $M$. amamiensis (sensu Sata 2015): KUZ Z2015 from Yakushima Town, Kagoshima Prefecture, Japan (Yakushima Island), Japan (site 5); KUZ Z1769 from Kodakarajima, Toshima Village, Kagoshima Prefecture (Kodakarajima Island), Japan (site 6); KUZ Z673, Z674 from Amami City, Kagoshima Prefecture, Japan (Amamioshima Island) (site 7); KUZ Z1770 from Yamato Village, Kagoshima Prefecture, Japan (Amamioshima Island) (site 8); M. japonica: KUZ Z1762 from Odawara City, Kanagawa Prefecture, Japan; KUZ Z1763 from Izunokuni City, Shizuoka Prefecture, Japan; KUZ Z630-Z632 from Fukuroi City, Shizuoka
Prefecture, Japan; KUZ Z636 from Kofu City, Yamanashi Prefecture, Japan; KUZ Z637, Z638 from Takasaki City, Gunma Prefecture, Japan; KUZ Z639 from Hachioji City, Tokyo, Japan; KUZ Z641, Z642, Z1765 from Tokushima City, Tokushima Prefecture, Japan; and KUZ Z645, Z1767 from Nagahama, Satsumasendai City, Kagoshima Prefecture, Japan (Shimokoshikijima Island) (Sata 2018).

\section{Systematics}

\section{Meteterakis formosensis sp. $\mathbf{n}$.}

http://zoobank.org/51F7462B-95D2-43AD-A4DA-0ECBD7E019FA Fig. 2

Meteterakis sp. 3; Sata 2018: figs 2, 3 (in part), table 1 (in part).

Type materials. Holotype: KUZ Z1779, whole specimen, adult male, obtained from the rectum of a Plestiodon chinensis specimen (KUZ R69425), collected from Mt. Guanyinshan, Bali District, New Taipei City, Taiwan $\left(25^{\circ} 08^{\prime} 53.1^{\prime \prime} \mathrm{N}, 121^{\circ} 25^{\prime} 47.3^{\prime \prime E}\right.$; elevation $199 \mathrm{~m}$ ) (site 10 in Fig. 1) on 20 March 2013. Paratypes: KUZ Z1777, Z1778, Z1783, Z1992 and Z1993, whole specimens, five adult males; KUZ Z1780-Z1782, three adult females, obtained from the same host specimen of the holotype; KUZ Z1994, one prepared slide of male spicules; and KUZ Z1995, a section of the anterior end and a remaining body (KUZ Z1994 is also derived from this individual), obtained from the same host specimen of the holotype.

Additional material. The following scincid lizard specimens, which were collected from Taiwan, were also dissected to reveal the geographic range of the new Taiwanese taxon: P. chinensis from Taipei City (KUZ R51443, R51444 and R51449-R51453), from New Taipei City (KUZ R46132, R46134 and R46136-R46139), and from Miaoli County (KUZ R70946, R70948-R70951, R70953 and R70963); Plestiodon leucostictus (Hikida, 1988) from Hualien City, Hualien County (KUZ R69421 and R69424); Plestiodon elegans (Thompson, 1912) from Taipei City (KUZ R66354), from the Xindian District, New Taipei City (KUZ R30191, R36205), from Miaoli County (KUZ R50394, R70957 and R70964), from Yilan County, (KUZ R36552), and from Tainan City (KUZ R70090 and R70091); and Eutropis longicaudata (Hallowell, 1857) from Tainan City, (KUZ R70089). One Meteterakis-like specimen (KUZ Z2021) was obtained from a P. chinensis specimen (KUZ R70948).

Type locality. Taiwan, New Taipei City: Bali District, Mt. Guanyinshan.

Type host. Plestiodon chinensis (Gray, 1838) (Reptilia, Scincidae); site of infection: rectum and small intestine.

Diagnosis. Relatively stout body, with narrow lateral and caudal alae; lateral alae commencing from region anteri- 


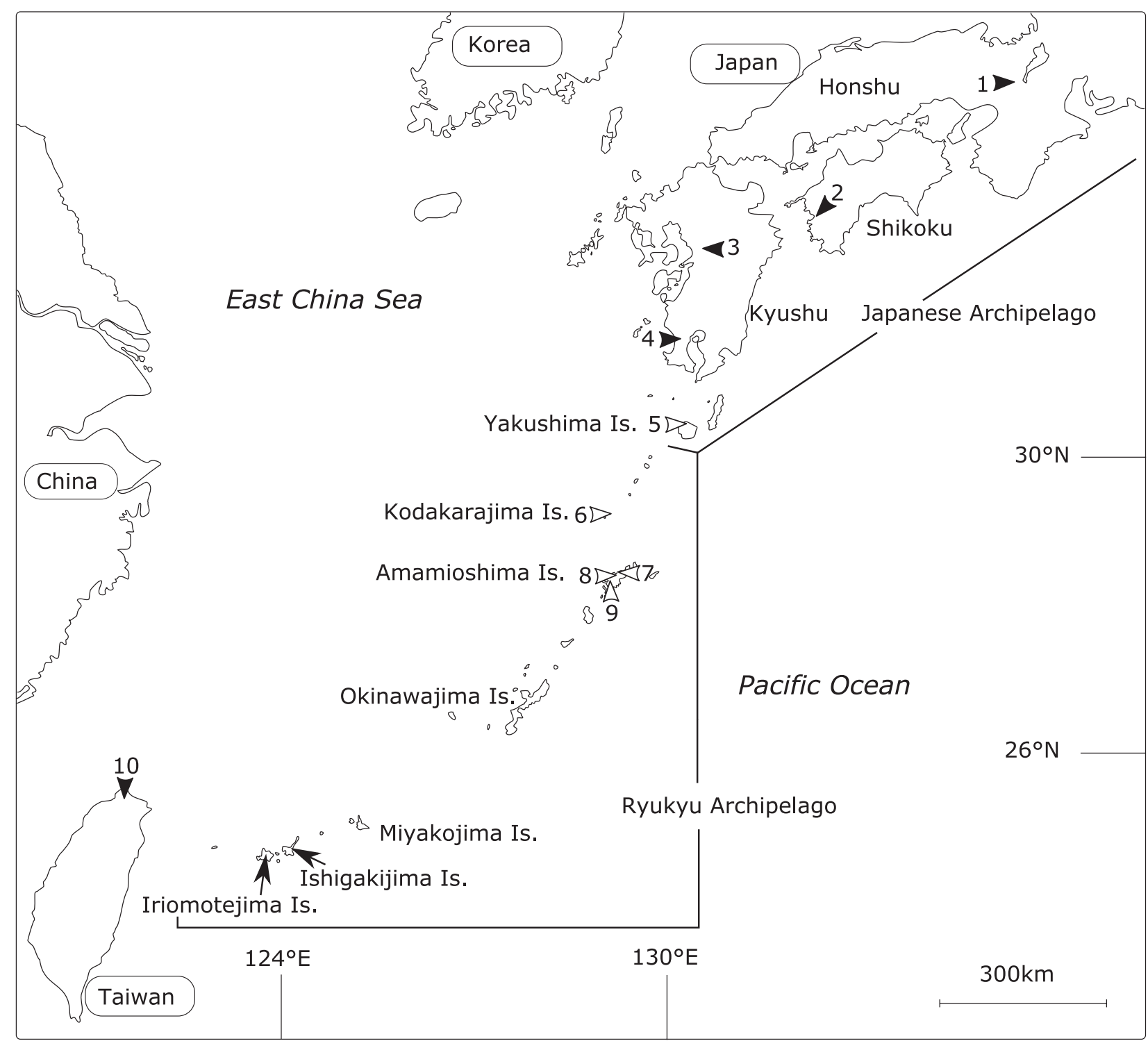

Figure 1. Map showing the known populations of Meteterakis Karve, 1930 inhabiting the Japanese Archipelago, the Ryukyu Archipelago and Taiwan: Meteterakis occidentalis sp. n. (sites 1-4), M. amamiensis Hasegawa, 1990 (sites 5-9; Hasegawa 1990, Sata 2015, 2018), and Meteterakis formosensis sp. n. (site 10). Solid arrows indicate the new species, and open arrows indicate $M$. amamiensis. Detailed site information can be found in Table 1.

or to nerve ring or front end of nerve ring in both sexes and ending at region near proximal end of spicule in male (never reaching region of preclocal sucker) or at region anterior to anus in female. Prevulval flap present and well developed in female. Gubernacular mass absent. Spicules with thin alae, funnel-shaped proximal ends, hyaline tips, and both proximal and distal ends bent ventrally. Right spicule, 437-510 long; left spicule 457-537 long. Each spicule with thick and long cuticular backing structures, not covered by cuticular pouch. Caudal papillae present in male, $8-13(N=4)$ pairs with additional papillae: $12-15$ $(N=4)$ on right side; $9-15(N=5)$ on left side.

Etymology. The specific name is an adjective, derived from the old name for Taiwan, which is the type locality of the new species.
Description. General. Body short and relatively stout with tapered extremities. Cephalic end with 3 lips, each lip with 2 minute apical papillae. Dorsal lip with a pair of cephalic papillae (each papilla with 2 minute papillae); each subventral lip with single papilla (each papilla with 2 minute papillae), 1 amphid and 1 smaller papillae. Flanges in inner edge of each lip unobservable. Esophagus comprise of pharynx, cylindrical portion and bulb. Bulb bearing three valves. lateral alae commencing from region anterior to nerve ring or front end of nerve ring in both sexes and ending at region near proximal end of spicule in male (never reaching region of preclocal sucker) or at region anterior to anus in female.

Male ( $N=6$; KUZ Z1777-Z1779, Z1783, Z1992 and Z1993). Body length $5.03 \mathrm{~mm}(4.84-5.67 \mathrm{~mm})$, maximum width 206 (151-228). Body length/body width = 
A

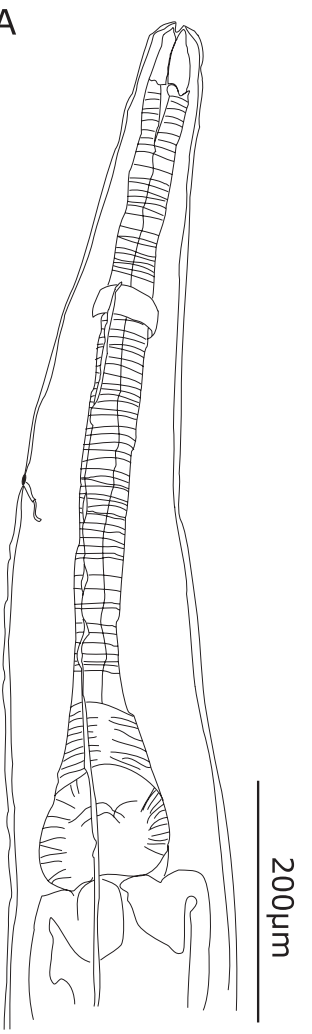

B

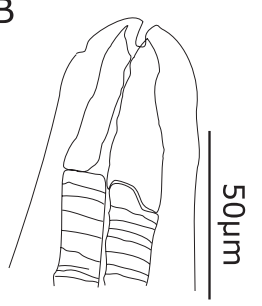

C

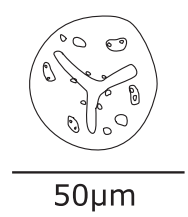

D

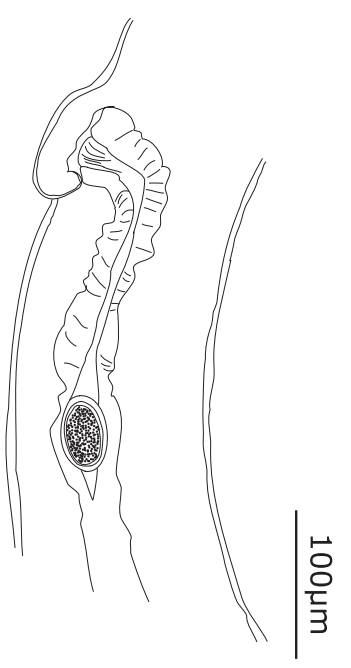

E

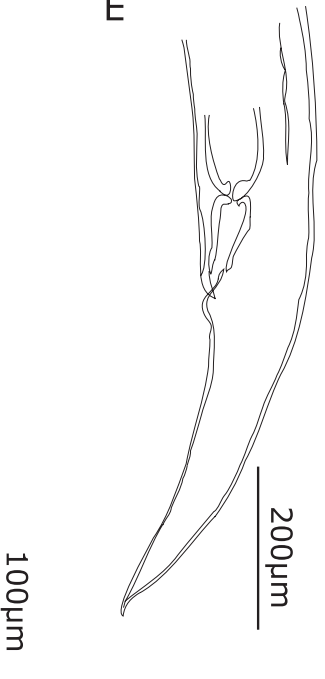

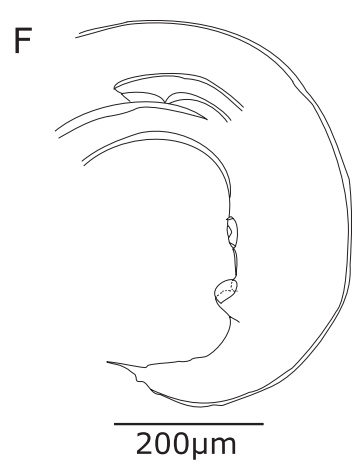

G

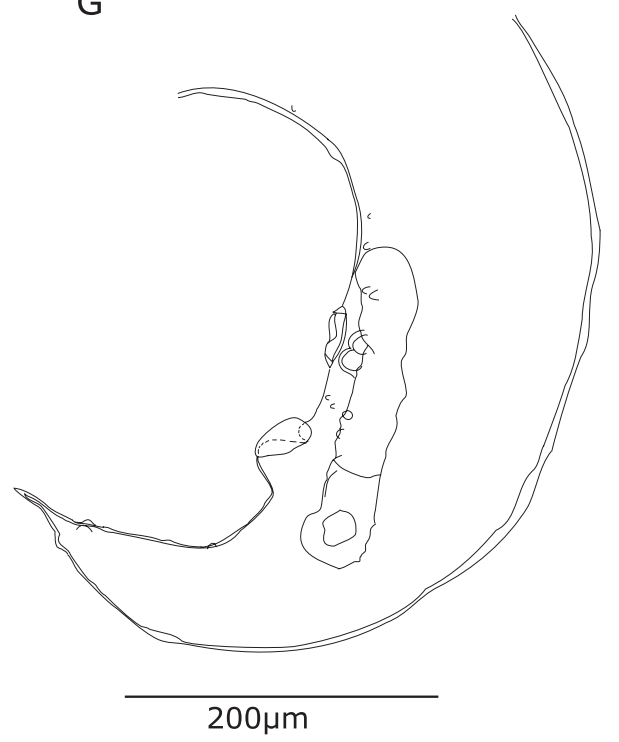

$\mathrm{H}$

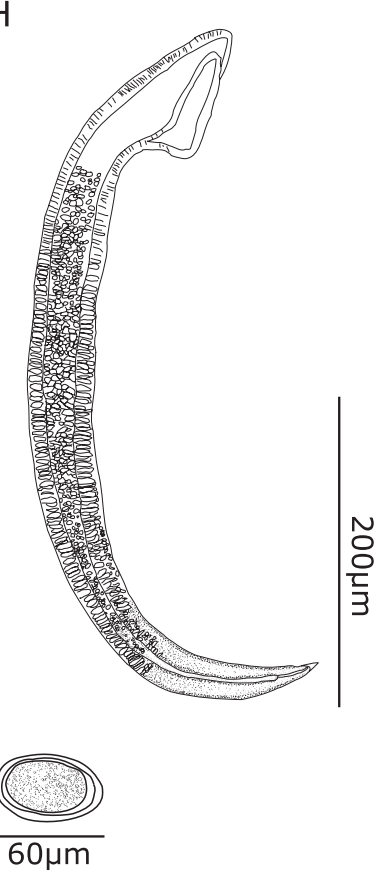

I

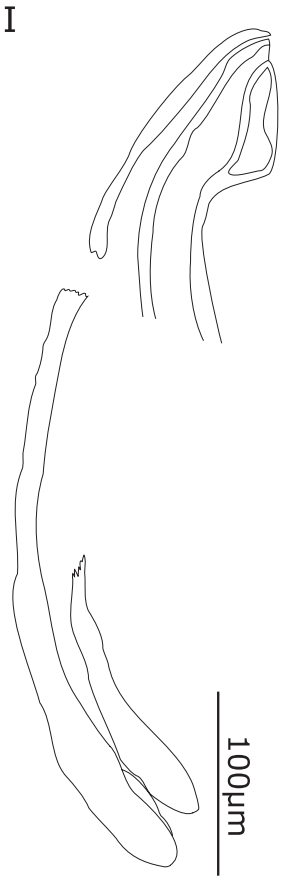

Figure 2. Meteterakis formosensis sp. n., holotype (KUZ Z1779: A, B, F, G), paratypes (KUZ Z1781: D, J; KUZ Z1782: E; KUZ Z1994: H, I; KUZ Z1995: C). A anterior region, lateral view; B pharynx, lateral view; C anterior end, apical view; D vulvar area of female, lateral view; $\mathbf{E}$ caudal region of female, lateral view; $\mathbf{F}$ caudal region of male, lateral view; $\mathbf{G}$ caudal papillae arrangement of male, lateral view; $\mathbf{H}$ spicule; I accessory of spicule; $\mathbf{J}$ egg. 
Table 1. Distributions of Meteterakis formosensis sp. n., Meteterakis occidentalis sp. n., and M. amamiensis Hasegawa, 1990.

\begin{tabular}{|c|c|c|c|c|}
\hline Species & Site \# & $\begin{array}{l}\text { Locality } \\
\end{array}$ & Geographic coordinates & References \\
\hline M. occidentalis sp. $\mathrm{n}$. & 1 & $\begin{array}{l}\text { Mt. Yoshida, Kyoto City, Kyoto Pref., } \\
\text { JP (Honshu) }\end{array}$ & $35^{\circ} 01^{\prime} 43.7^{\prime \prime} \mathrm{N}, 135^{\circ} 47^{\prime} 09.4^{\prime \prime} \mathrm{E}$ & Sata (2015); This study \\
\hline M. occidentalis sp. $\mathrm{n}$. & 2 & Uwajima City, Ehime Pref., JP (Shikoku) & $33^{\circ} 13^{\prime} 56.8^{\prime \prime} \mathrm{N}, 132^{\circ} 33^{\prime} 13.7^{\prime \prime} \mathrm{E}$ & Sata (2018); This study \\
\hline M. occidentalis sp. $\mathrm{n}$. & 3 & Kumamoto City, Kumamoto Pref., JP (Kyushu) & $32^{\circ} 47^{\prime} \mathrm{N}, 130^{\circ} 41^{\prime} \mathrm{E}$ & Sata (2015); This study \\
\hline M. occidentalis sp. $\mathrm{n}$. & 4 & Kagoshima City, Kagoshima Pref., JP (Kyushu) & $31^{\circ} 35^{\prime} 39.76^{\prime \prime} \mathrm{N}, 130^{\circ} 27^{\prime} 31.55^{\prime \prime} \mathrm{E}$ & Sata (2015); This study \\
\hline M. amamiensis & 5 & $\begin{array}{c}\text { Yakushima Town, Kagoshima Pref., } \\
\text { JP (Yakushima Island) }\end{array}$ & $30^{\circ} 27^{\prime} \mathrm{N}, 130^{\circ} 29^{\prime} \mathrm{E}$ & Sata (2015); This study \\
\hline M. amamiensis & 6 & $\begin{array}{c}\text { Kodakarajima, Toshima Village, Kagoshima } \\
\text { Pref., JP (Kodakarajima Is.) }\end{array}$ & $29^{\circ} 13^{\prime} 22.6^{\prime \prime} \mathrm{N}, 129^{\circ} 19^{\prime} 39.2^{\prime \prime} \mathrm{N}$ & Sata (2018); This study \\
\hline M. amamiensis & 7 & $\begin{array}{c}\text { Amami City, Kagoshima Pref., } \\
\text { JP (Amamioshima Is.) }\end{array}$ & $28^{\circ} 24^{\prime} 01.3^{\prime \prime} \mathrm{N}, 129^{\circ} 28^{\prime} 33.6^{\prime \prime} \mathrm{E}$ & Sata (2015); This study \\
\hline M. amamiensis & 8 & $\begin{array}{c}\text { Yamato Village, Kagoshima Pref., } \\
\text { JP (Amamioshima Is.) }\end{array}$ & $28^{\circ} 21^{\prime} 30.8^{\prime \prime} \mathrm{N}, 129^{\circ} 20^{\prime} 11.7^{\prime \prime} \mathrm{E}$ & Sata (2018); This study \\
\hline M. amamiensis & 9 & $\begin{array}{c}\text { Mt. Yuwan, Uken Village, Kagoshima Pref., } \\
\text { JP (Amamioshima Is.) }\end{array}$ & $\mathrm{N} / \mathrm{A}$ & Hasegawa (1990) \\
\hline M. formosensis sp. $\mathrm{n}$. & 10 & $\begin{array}{c}\text { Mt. Guanyinshan, Bali District, } \\
\text { New Taipei City, TW }\end{array}$ & $25^{\circ} 08^{\prime} 53.1^{\prime \prime} \mathrm{N} ; 121^{\circ} 25^{\prime} 47.3^{\prime \prime} \mathrm{E}$ & Sata (2018); This study \\
\hline
\end{tabular}

24.4 (24.8-36.3). Diameter of head 46 (38-50). Total length of esophagus 724 (681-774) long with width of 36 (31-44) at cylindrical portion. Body length/esophagus length $=7.0$ (7.0-7.8). Pharynx 47 (34-45) long, bulb 85 (79-95) long by 110 (91-114) wide. Grooves between lips shallow and $8.2(7.5-9.3)$ long. Nerve ring and excretory pore 221 (207-243) and 396 (337400), respectively, from cephalic end. Spicules equal or slightly different, with narrow alae, strongly chitinized, tessellated from 153 (120-141) from proximal end to distal end in right spicule (i.e. corresponding to $68.1 \%$ [68.3\%-75.7\%] of total length), and from 66 (95-159) to distal end in left spicule (i.e. corresponding to $86.8 \%$ [65.2\%-81.9\%] of total length); both proximal and distal ends bent ventrally, with wide funnel-shaped proximal ends, and pointed hyaline distal ends. Right spicule 480 (437-510) long (i.e. corresponding to 9.5\% [8.0\%$9.8 \%$ ] of body length), left spicule 500 (457-537) (i.e. corresponding to $9.9 \%$ [8.3\%-10.5\%] of body length). Each spicule with thick and long cuticular backing structure, not covered by cuticular pouch. Gubernacular mass absent. Narrow caudal alae present, supported by three pairs of large papillae. Caudal papillae present, 13 $(8-13)(N=4)$ pairs with additional papillae: $13(12-15)$ $(N=4)$ on right side; $15(9-15)(N=5)$ on left side. Occasionally, single median papilla present. Among 13 (8-13) pairs: $1-4$ pairs anterior to preclocal sucker; 2 large pairs supporting caudal alae around sucher; 1-3 small pairs around sucker; 0-2 pairs between sucker and cloaca; 1 large pair supporting caudal alae at lateral to posterior cloacal lip; 0-1 pair immediately posterior to posterior cloacal lip; and 0-2 pairs in caudal region. Precloacal sucker 47 (35-47) in diameter, 54 (26-50) from cloaca. Posterior cloacal lip developed. Tail bent ventrally, conical with pointed tip, and 304 (238-315) long. Body length/tail length $=16.6(15.4-23.0)$.

Female ( $N=3$; KUZ Z1780-Z1782). Body length 6.05 $\mathrm{mm}$ (5.56-6.30 mm), and maximum width 224 (200-
244). Body length/body width $=27.0$ (25.8-27.8). Diameter of head 51 (49-52). Total length of esophagus 783 (753-806) long with width of 45 (39-50) at cylindrical portion. Body length/esophagus length $=7.7$ (7.0-8.4). Pharynx 51 (38-61) long; bulb 95 (91-99) long by 108 (104-114) wide. Grooves between lips shallow and 8.5 (7.2-9.4) long. Nerve ring and excretory pore 230 (228232) and 367 (359-372), respectively, from cephalic end. Vulva $2.71 \mathrm{~mm}(2.44-2.87 \mathrm{~mm})$ from cephalic end, and located at anterior to middle of body (44.8\% [43.9\%$45.6 \%$ ] of body length). Prevulval flap well developed. Vagina muscular running posteriorly. Tail long conical, slightly bent ventrally, and 560 (518-583) long. Body length/tail length $=10.8(10.7-10.9)$. Eggs elliptical, 60 (49-68) by $41(34-51)(N=29)$, thick shelled, containing morula stage embryos.

Occurrence. This new species was located on Mt. Guanyinshan, Bali District, New Taipei City, Taiwan (type locality) (site 10 in Fig. 1). Although a Meteterakis-like specimen (KUZ Z2021) with undeveloped spicules was obtained from the rectum of a $P$. chinensis specimen (KUZ R70948) from Miaoli County, Taiwan, its taxonomic account is unclear. $P$. chinensis is the only known host of this species.

Comparisons. This new species can be discriminated from almost half of the other Meteterakis species by the lengths of the spicules. Because M. formosensis sp. $\mathrm{n}$. has spicules that are $437-537 \mu \mathrm{m}$ in length, it can be distinguished from the following eight congeners, which are diagnosed by their spicules longer than $600 \mu \mathrm{m}: M$. aurangabadensis Deshmukh \& Choudhari, 1980 (620$720 \mu \mathrm{m})$, M. karvei Naidu \& Thakare, 1981 (660-840 $\mu \mathrm{m})$, M. longispiculata (Baylis, 1929) (630-680 $\mu \mathrm{m})$, M. louisi Inglis, $1958(970-1100 \mu \mathrm{m})$, M. singaporensis (Sandosham, 1953) (740-960 $\mu \mathrm{m})$, M. striaturus Oshmarin \& Demshin, $1972(680 \mu \mathrm{m})$, M. vaucheri 
Adamson, 1986 (1057-1242 $\mu \mathrm{m})$ and $M$. wangi Zhang \& Zhang, $2011(740-930 \mu \mathrm{m})$. This new species is also distinguishable from M. bufonis (Biswas \& Chakravarty, 1963) (left, $270 \mu \mathrm{m}$; right, $310 \mu \mathrm{m}$ ), M. gambhiri Gambhir et al., 2006 (220-270 $\mu \mathrm{m})$, M. govindi (180-270 $\mu \mathrm{m}$; Karve 1930, Inglis 1958) and M. mabuyi (Chakravarty, 1944) $(300 \mu \mathrm{m})$, because its spicules are longer than $400 \mu \mathrm{m}$. Moreover, the new species differs from $M$. lyriocephali (Crusz \& Ching, 1975) because the spicules are similar in length on the left $(457-537 \mu \mathrm{m})$ and right $(437-510 \mu \mathrm{m})$ sides (in M. lyriocephali: left, 595-754 $\mu \mathrm{m}$; right, 340-561 $\mu \mathrm{m})$.

In addition to the spicule length, the new species is distinguishable from the eight congeners by the following characteristics of spicules: proximal end wide, funnel-shaped and ventrally bent vs. proximal end slightly widened in M. ishikawanae (Hasegawa 1987) and $M$. wonosoboensis Purwaningshi, 2015 or vs. proximal end straight in M. guptai Gupta \& Naiyer, 1993 and M. triaculeata (Kreis, 1933) (Inglis 1958); surface smooth, vs. rough surface in M. saotomensis Junker et al., 2015; and spicule alae narrow vs. wider in M. baylisi Inglis, 1958, M. crombiei Bursey et al., 2005 and M. sinharajensis Crusz \& Ching, 1975.

Meteterakis formosensis sp. $\mathrm{n}$. is distinguished from M. lombokensis Purwaningshi et al., 2016 by the presence of a well-developed prevulval flap in the female. Additionally, this species possesses a $35-47 \mu \mathrm{m}$ (diameter) preclocal sucker and elliptically-shaped eggs. These characteristics can be used to discriminate this new species from M. andamanensis Soota \& Chaturvedi, 1972, which has a 55-66 $\mu \mathrm{m}$ (diameter) preclocal sucker and spherical-shaped eggs. The number of caudal papillae (9-15) on both lateral sides of the new species can distinguish it from M. paucipapillosa Wang, 1980 because the latter possesses only 6 caudal papillae on both lateral sides. The new taxon is clearly distinguishable form M. japonica and M. hurawensis Bursey et al., 2017 by the absence of a gubernacular mass (Wilkie 1930, Inglis 1958, Bursey et al. 2017). M. formosensis sp. n. bears narrow lateral alae ending at the region near the proximal end of the spicule in the male or at the region anterior to the anus in the female. Thus, this new species differs from $M$. amamiensis, which is diagnosed by possession of the wider lateral alae ending at the preclocal region in the male, and at the region near the posterior end in the female (Hasegawa 1990).

Morphologically, M. formosensis sp. n. most resembles $M$. occidentalis sp. n., which is described below, but it differs from the latter species by the female having a relatively stout body (body length/body wide: $25.8-27.8$ in M. formosensis sp. n. vs. 31.8-41.2 in M. occidentalis sp. n.), relatively longer tail length in the female (body length/tail length: 10.7-10.9 in M. formosensis sp. n. vs. 13.6-17.8 in M. occidentalis sp. n.), spicules with hyaline tips (lacking in M. occidentalis sp. n.) and well-developed backing structures for spicules (undeveloped in $M$. occidentalis $\mathrm{sp} . \mathrm{n}$.).

\section{Meteterakis occidentalis sp. n.}

http://zoobank.org/95FED6DF-22ED-486B-8AD2-B950FEDE87B1

Fig. 3

Meteterakis amamiensis; Sata 2015: 17 (in part); Sata 2018: figs 2, 3 (in part), table 1 (in part).

Type materials. Holotype: KUZ Z2000, whole specimen, adult male, obtained from the small intestine of a P. japonicus specimen (KUZ R69034), collected from Mt. Yoshida, Kyoto City, Kyoto Prefecture, Japan $\left(35^{\circ} 01^{\prime} 43.7^{\prime \prime} \mathrm{N}, 135^{\circ} 47^{\prime} 09.4^{\prime \prime E}\right.$; elevation $70 \mathrm{~m}$ ) (site 1 in Fig. 1) on 16 May 2012. Paratypes: KUZ Z1996-Z1999 and Z2002-Z2008, whole specimens, four adult males and seven adult females, obtained from the rectum and small intestine of the same specimen of holotype's host and another P. japonicus specimen (KUZ R69036), data same as those from the holotype's host-specimen; KUZ Z2001, whole specimen, adult male, obtained from the small intestine of a P. japonicus specimen (KUZ R69575), collected from Ohura, Uwajima City, Ehime Prefecture, Japan (33'13'56.8"N, 132 33'13.7"E; elevation 4 m) (site 2 in Fig. 1) on 8 April 2013; KUZ Z2009, prepared slides of male spicules with the spicule pouch; Z2010, prepared slides of male spicules; KUZ Z2011 and Z2012, remaining body specimens of KUZ Z2009 and Z2010, respectively; KUZ Z2013, a section of the anterior end and a remaining body. KUZ Z2009, Z2010 and Z2013 were obtained from the rectum of a $P$. japonicus specimen (KUZ R69030), collected from same locality as the holotype's host-specimen on 9 May 2012.

Additional material. To reveal the geographic range of M. occidentalis sp. n., the following specimens deposited in the KUZ collection were examined: $M$. amamiensis (sensu Sata 2015): KUZ Z2014 from Kumamoto City, Kumamoto Prefecture, Japan (site 3 in Fig. 1), and KUZ Z658 and Z2022 from Kagoshima City, Kagoshima Prefecture, Japan (site 4 in Fig. 1).

Type locality. Japan, Kyoto: Kyoto, Mt. Yoshida.

Type host. Plestiodon japonicus (Peters, 1864) (Reptilia, Scincidae); site of infection: rectum and small intestine.

Diagnosis. Short and slender body, with narrow lateral and caudal alae; lateral alae commencing from region anterior to nerve ring in both sexes and ending at region near proximal end of spicule (never reaching region of preclocal sucker) in male or at region anterior to anus in female. Prevulval flap well developed in female. Male with well-developed posterior cloacal lip. Gubernacular mass absent. Spicules with narrow alae, funnel-shaped proximal end, and both proximal and distal ends bent ventrally. Right spicule 359-517 long, left spicule 368-538 long. Dorsal surfaces of each spicule covered by thin cuticular pouch. Caudal papillae present in male, $7-11(N=6)$ pairs with additional papillae: $10-14(N=6)$ on right side; 10-14 $(N=6)$ on left side. 

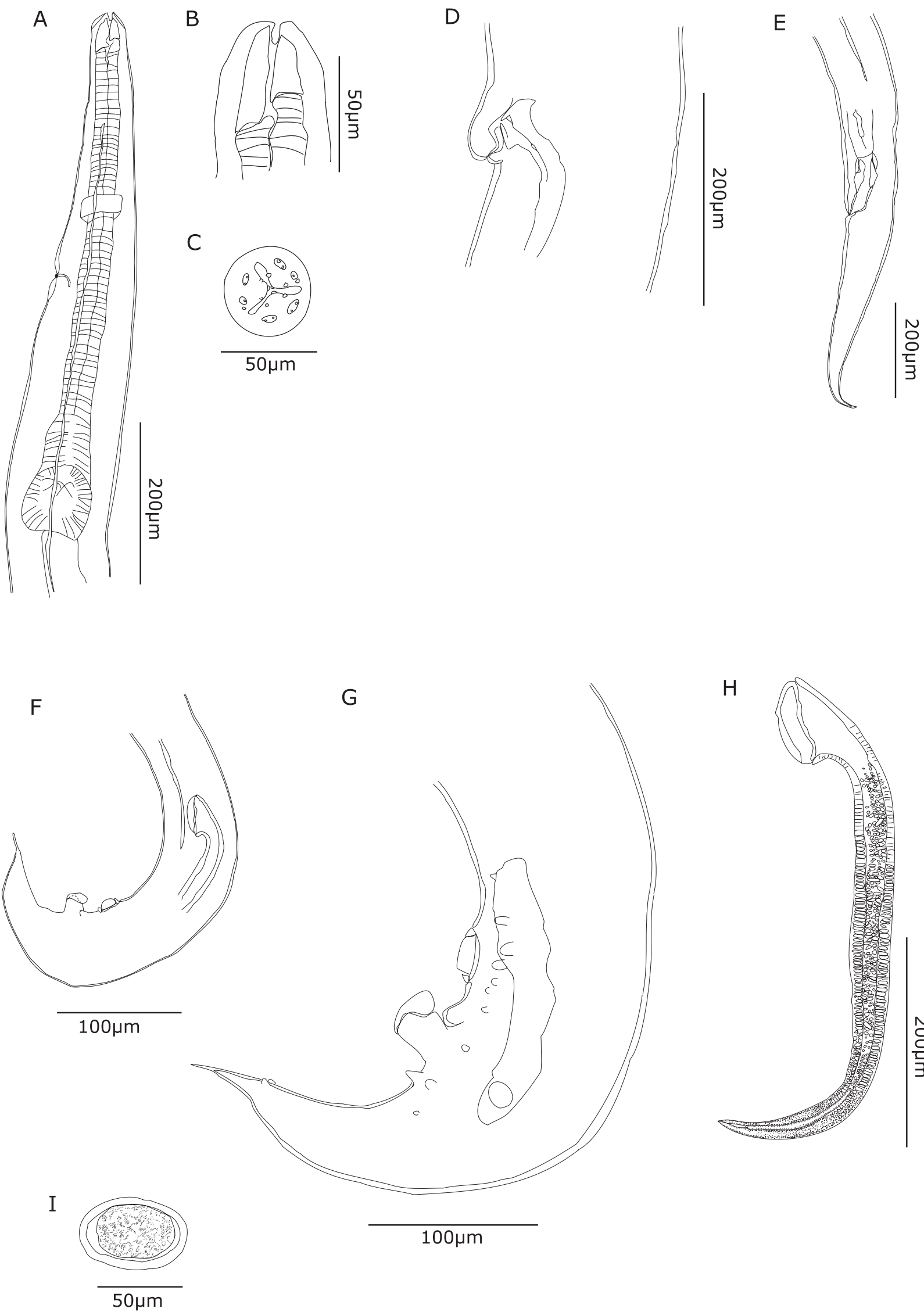

G

$\mathrm{H}$
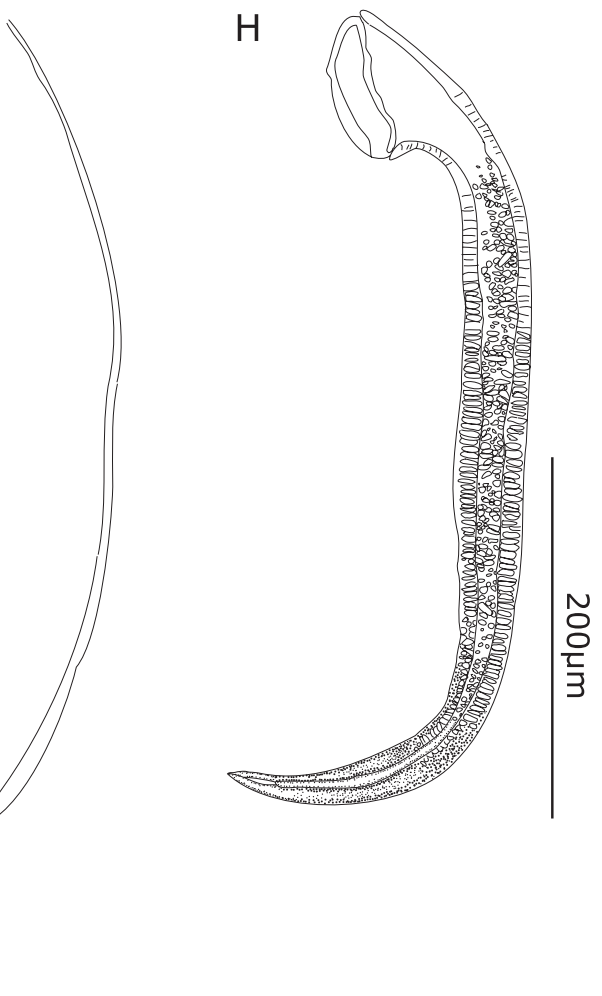

Figure 3. Meteterakis occidentalis sp. n., holotype (KUZ Z2000: A, B, F, G), paratypes (KUZ Z2005: D, E, I; KUZ Z2010: H; KUZ Z2013: C). A anterior region, lateral view; B pharynx, lateral view; C anterior end, apical view; $\mathbf{D}$ vulvar area of female, lateral view; $\mathbf{E}$ caudal region of female, lateral view; $\mathbf{F}$ caudal region of male, lateral view; $\mathbf{G}$ caudal papillae arrangement of male, lateral view; H spicule; I egg. 
Etymology. The specific name is a Latin adjective in the nominative singular, occidentalis (western), referring to its distribution in the western Japanese Archipelago.

Description. General. Body short and slender with tapered extremities. Cephalic end with 3 lips, each lip with 2 minute apical papillae. Dorsal lip with a pair of cephalic papillae (each papilla with 2 minute papillae); each subventral lip with single papilla (each papilla with 2 minute papillae), 1 amphid and 1 papilla. Inner edge of each lips with flange. Esophagus comprise of pharynx, cylindrical portion and bulb. Bulb has three valves. Narrow lateral alae present in both sexes, commencing from region anterior to nerve ring in both sexes and ending at region near proximal end of spicule (never reaching region of preclocal sucker) in male or at region anterior to anus in female.

Male ( $N=6$; KUZ Z1996-Z2001). Body length $4.68 \mathrm{~mm}$ (4.19 mm -5.75 mm), maximum width 132 (120-163). Body length/body width $=35.5$ (29.2-39.7). Diameter of head 42 (42-47). Total length of esophagus 621 (621-732) long with width of 39 (32-44) wide at cylindrical portion. Body length/esophagus length $=7.5$ (6.7-7.9). Pharynx 36 (35-47) long, bulb 83 (65-97) long by 83 (84-100) wide. Grooves between lips shallow and 7.3 (7.0-13.5) long. Nerve ring and excretory pore 217 (203-241) and 328 (307$350)$, respectively, from cephalic end. Spicules with narrow alae, equal or slightly different, strongly chitinized, tessellated from 95 (78-104) from proximal end to distal end in right spicule (i.e. corresponding to $76.7 \%$ [76\%-84\%] of total length), and from 101 (43-118) to distal end in left spicule (i.e. corresponding to $76 \%$ [74.7\%-91.4\%] of total length), both proximal and distal ends bent ventrally, wide funnel-shaped proximal end and distal end pointed. Right spicule 408 (359-517) long (i.e. corresponding to $8.7 \%$ [8.6\%-10.3\%] of body length), left spicule 421 (368-538) (i.e. corresponding to $9.0 \%$ [8.3\%-10.5\%] of body length). Dorsal surface of each spicules covered by thin cuticular pouch. Gubernacular mass absent. Narrow caudal alae present, supported by three pairs of large papillae. Caudal papillae present, $11(7-11)(N=6)$ pairs with additional papillae: $14(10-12)(N=6)$ on right side; $14(10-14)(N=6)$ on left side. Occasionally, single median papilla present. Among 11 (7-11) pairs: 1-2 pairs anterior to preclocal sucker; 2 large pairs supporting caudal alae and $0-1$ small pair lateral to preclocal sucker; 0-2 pairs between posterior region of sucker and cloaca; 1 large pair supporting caudal alae at lateral to posterior cloacal lip; 0-2 pair immediately posterior to posterior cloacal lip; 1-3 pairs posterior region of tail; 0-1 pair lateral to cloaca. Precloacal sucker 36 (32-36) in diameter and 33 (23-38) from cloaca. Posterior cloacal lip developed. Tail bent ventrally, conical, with pointed tip, 258 (234-282) long. Body length/tail length $=18.1$ (17.9-20.4).

Female (N=7; KUZ Z2002-Z2008). Body length 5.49 $\mathrm{mm}$ (4.85 mm-5.98 mm), maximum width 158 (145-182). Body length/body width $=34.8$ (31.8-41.2). Diameter of head 48 (41-56). Total length of esophagus 731 (648-798) long with width of $37(31-42)$ at cylindrical portion. Body length/esophagus length $=7.5$ (6.7-8.0). Pharynx 43 (38-
52) long; bulb 94 (87-106) long by 90 (79-101) wide. Grooves between lips shallow and 10.5 (7.3-13) long. Nerve ring and excretory pore 230 (162-275) and 355 (311-388), respectively, from cephalic end. Vulva 2.36 $\mathrm{mm}$ (2.09-2.54 mm) from cephalic end. Vulva located at anterior to middle of body $(43.0 \%[39.9 \%-47.4 \%]$ of body length). Prevulval flap well developed. Vagina muscular running posteriorly. Tail long conical, slightly bent ventrally, 353 (329-415) long, with a few specimens possessing a few small papillae. Body length/tail length $=15.6$ (13.6-17.8). Eggs elliptical, 62 (52-72) by 40 (32-47) $(N=70)$, thick shelled, containing morula stage embryo.

Occurrence. Meteterakis occidentalis sp. n. occurs in the following locations in Japan: Kyoto City, Kyoto Prefecture, Honshu (site 1 in Fig. 1); Uwajima City, Ehime Prefecture, Shikoku (site 2 in Fig. 1); Kumamoto City, Kumamoto Prefecture, Kyushu (site 3 in Fig. 1); and Kagoshima City, Kagoshima Prefecture, Kyushu (site 4 in Fig. 1). P. japonicus is the only known host of this species (Sata 2015, 2018).

Notes on the life cycle. Most Meteterakis nematodes collected from recta were adult individuals. Several larval nematodes were collected from the small intestines of the host individuals, which were inhabited by M. occidentalis sp. n., and a small number of ensheathed Meteterakis were also found from there. The rate of females having eggs in hosts' small intestines and recta were $36.2 \%$ $(21 / 58)$ and $72.5 \%(50 / 69)$, respectively.

Comparisons. M. occidentalis sp. n. differs from M. formosensis sp. n. as discussed above. Because most of the morphological characteristics of $M$. occidentalis sp. n. are concordant with those of $M$. formosensis sp. n., this new species can be distinguished from the other congeners by the features mentioned in comparisons with $M$. formosensis sp. n. and the other Meteterakis species. Therefor, $M$. occidentalis sp. $\mathrm{n}$. can receive the taxonomic status of a distinct species within the genus.

\section{Discussion}

Heterakidae has been classified into three subfamilies, Heterakinae, Spinicaudinae, and Meteterakinae (Inglis 1957). While the life cycles of heterakine and spinicaudine nematodes have been well documented, the life cycle of meteterakine species remains unknown (Anderson 2000). During the dissection and examination of host reptile specimens, larval nematodes were collected from the small intestines of $P$. japonicus. Because those larvae often co-occurred with adult worms of $M$. occidentalis sp. n. and/or ensheathed Meteterakis nematodes in the host materials, they are likely to be $M$. occidentalis sp. n. larval individuals.

Most of the $M$. occidentalis sp. n. specimens of both sexes collected from the recta were at the adult stage. Moreover, mature female of $M$. occidentalis sp. n. bearing 
eggs occurred less frequently in the hosts' small intestines than in the recta, suggesting that the larvae of this species may mature in the small intestine and then migrate to the rectum to oviposit. A similar life cycle has been recorded for two spinicaudine species that are parasites in the rectum of Malagasy chameleons (Anderson 2000). The present results provide new insights into the life cycle of the meteterakine nematodes and indicates that their life cycles may resemble those of spinicaudine species.

The spicule length, which has been regarded as a useful taxonomic character of the genus Meteterakis (e.g. Junker et al. 2015), exhibits certain intraspecific variations. Moreover, the characteristic of spicule length sometimes overlaps with those of other congeners. In contrast, the present study revealed an obvious morphological difference between the two morphologically similar species, M. occidentalis sp. $\mathrm{n}$. and $M$. amamiensis, in the width and ending positions of the lateral alae. Because the characteristics of the lateral alae in M. occidentalis sp. n. showed much less intraspecific variation, lateral alae can be used as a diagnostic character among the Meteterakis species. The combination of the lateral alae and other traditional taxonomic character within this genus may help discriminate the species of Meteterakis. However, Meteterakis species, which were described previously, sometimes lack morphological descriptions of their lateral alae (e.g. Inglis 1958, Gambhir et al. 2006). Therefor, the characteristics of their lateral alae should be revisited by future taxonomic revisions. Additionally, it is preferable that future descriptive studies of new Meteterakis species contain the characteristics of lateral alae.

Because a previous phylogenetic study (Sata 2018) did not include "M. amamiensis" (sensu Sata 2015) specimens from Kumamoto City, Kumamoto Prefecture, Japan (Kyushu) and Yakushima Town, Kagoshima Prefecture (Yakushima Island), Japan, their taxonomical accounts remained unclear. The present morphological observations revealed that the Meteterakis specimens from Kumamoto Prefecture, and Yakushima Island are M. occidentalis sp. n., and M. amamiensis, respectively, based on the characteristics of their lateral alae. Although the herpetofauna of Yakushima Island is closely related to that of Kyushu, and their compositions have genetically diverged deeply from each congeneric species on the Amamioshima Islands (Tanaka-Ueno et al. 1998, Brandley et al. 2012), M. amamiensis is indigenous to Yakushima and Amamioshima Islands. Thus, the geographic range of this nematode species would be obviously discordant with the host biogeography.

This discordant pattern between the endoparasites and their host species was indicated by the two unidentified Meteterakis species on Ishigakijima and Iriomotejima Islands (Sata 2018). Therefore, the range of each Meteterakis species cannot always be predicted by the host's distribution pattern. Thus, the species diversity of Meteterakis should be revealed by geographically exhaustive faunal and taxonomic surveys. Moreover, the taxonomic account of the unidentified Meteterakis on Ishigakijima and Iriomotejima Islands should be clarified by a future study using appropriate specimens of the species.

\section{Acknowledgements}

The author is grateful to K. Kurita (Kyoto University) for providing host specimens; T. Hikida (Kyoto University) for useful comments on this study and for allowing me to dissect the lizard specimens of the KUZ collection; and T. Nakano and T. Okamoto (Kyoto University) for useful comments on this study. I thank L. Benyon from Edanz Group (www.edanzediting.com/ac) for editing a draft of this manuscript, and CR. Bursey for reviewing of the early version of this manuscript. The open access publication of this manuscript was supported by the Museum für Naturkunde.

\section{References}

Adamson ML (1986) Meteterakis vaucheri n. sp. (Nematoda; Heterakoidea) from Varanus grayi (Varanidae) in the Philippines. Canadian Journal of Zoology 64: 814-817. https://doi.org/10.1139/z86-122 Anderson RC (2000) Nematode Parasites of Vertebrates: Their Development and Transmission ( $2^{\text {nd }}$ edn). CABI Publishing, Wallingford, 650 pp. https://doi.org/10.1079/9780851994215.0000

Baker MR (1984) The systematic and zoogeography of Spinicaudinae and Meteterakinae (Heterakoidea: Nematoda) parasitic in reptiles and amphibians. Systematic Parasitology 6: 275-287. https://doi. org/10.1007/BF00012206

Baker MR (1987) Synopsis of the Nematoda parasitic in amphibians and reptiles. Memorial University of Newfoundland Occasional Papers in Biology 11: 1-325.

Baylis HA (1929) Some new parasitic nematodes and cestodes from Java. Parasitology 21:256-265.https://doi.org/10.1017/S0031182000022940 Biswas PK, Chakravarty GK (1963) The systematic studies of the zoo-parasitic oxyuroid nematodes. Zeitschrift Für Parasitenkunde 23: 411-428. https://doi.org/10.1007/BF00259929

Brandley MC, Ota H, Hikida T, de Oca ANM, Fería-Ortíz M, Guo X, Wang Y (2012) The phylogenetic systematics of blue-tailed skinks (Plestiodon) and the family Scincidae. Zoological Journal of the Linnean Society 165: 163-189. https://doi.org/10.1111/j.1096-3642.2011.00801.x

Bursey CR, Goldberg SR, Kraus F (2005) Endoparasites in Sphenomorphus jobiensis (Sauria: Scincidae) from Papua New Guinea with description of three new species. Journal of Parasitology 91: 13851394. https://doi.org/10.1645/GE-3502.1

Bursey CR, Goldberg SR, Siler CD, Brown RM (2017) New species of Meteterakis (Nematoda: Heterakidae) in Brachymeles spp. (Squamata: Scincidae) from the Philippines. Comparative Parasitology 84: 149-154. https://doi.org/10.1654/1525-2647-84.2.149

Bursey CR, Goldberg SR, Telford Jr SR (2005) Plagiorchis taiwanensis (Digenea: Plagiorchiidae), Kurilonema markovi (Nematoda: Rhabdiasidae) and other helminths in Eumeces latiscutatus (Scincidae) and Takydromus tachydromoides (Lacertidae) from Japan. Comparative Parasitology 72: 234-240. https://doi.org/10.1654/4170

Chakravarty GK (1944) On the nematode worms in the collection of the zoological laboratory, University of Calcutta, Part I. Families Heterakidae and Kathlaniidae. Journal of the Department of Science University of Calcutta 1: 70-77.

Crusz H, Ching CC (1975) Parasites of the relict fauna of Ceylon VI. More new helminths from Amphibians and Reptiles, with a new 
host-record and redescription of Acanthocephalus serendibensis Crusz and Mills, 1970. Annales de Parasitologie 50: 531-558. https://doi.org/10.1051/parasite/1975505531

Deshmukh PG, Choudhari AC (1980) Meteterakis aurangabadensis n. sp. from toad, Bufo melanostictus. Indian Journal of Parasitology 4: 37-40.

Gambhir RK, Tarnita TH, Chinglenkhomba A, Gyaneswori I, Indrani CH (2006) A new species of the genus Meteterakis Karve, 1930 (Nematoda: Heterakidae) from Bufo melanostictus Schneider. Flora and Fauna 12: 57-59.

Goldberg SR, Bursey CR (2002) Helminths of 10 species of anurans from Honshu, Japan. Comparative Parasitology 69: 162-176. https:// doi.org/10.1654/1525-2647(2002)069[0162:HOSOAF]2.0.CO;2

Gray JE (1838) Catalogue of the slender-tongued saurians, with descriptions of many new genera and species. Annals of Natural History 2: 287-293. https://doi.org/10.1080/00222933809496676

Gupta V, Naiyer N (1993) On a new nematode Meteterakis guptai sp. nov. from a lizard Calotes versicolor (Daudin) from Lucknow. Indian Journal of Helminthology 45: 184-187.

Hallowell E (1857) Notice of some new and rare species of Scincidae in the collection of the Academy of Natural Sciences of Philadelphia. Transactions of the American Philosophical Society 11: 71-82. https://doi.org/10.2307/3231927

Hasegawa H (1984) Helminth fauna of five Okinawan amphibian species. The Biological Magazine Okinawa 22: 11-22.

Hasegawa H (1987) Meteterakis ishikawanae sp. n. (Nematoda: Heterakidae) from the frogs, Rana ishikawae, on Okinawa Island, Japan. Proceedings of the Helminthological Society of Washington 54: 237-241.

Hasegawa H (1990) Helminths collected from amphibians and reptiles on Amami-oshima Island, Japan. Memoirs of the National Science Museum, Tokyo 23: 83-92.

Hasegawa H (1992) Parasitic helminthes collected from amphibians and reptiles on Kume-jima Island, Okinawa, Japan. The Biological Magazine Okinawa 30: 7-13.

Hasegawa H, Asakawa M (2004) Parasitic nematodes recorded from amphibians and reptiles in Japan. Current Herpetology 23: 27-35. https://doi.org/10.5358/hsj.23.27

Hikida T (1988) A new white-spotted subspecies of Eumeces chinensis (Scincidae: Lacertilia) from Lutao Island, Taiwan. Japanese Journal of Herpetology 12: 119-123. https://doi.org/10.5358/hsj1972.12.3_119

Inglis WG (1957) A review of the nematode superfamily Heterakoidea. The Annals and Magazine of Natural History, Series 12(10): 905912. https://doi.org/10.1080/00222935708656094

Inglis WG (1958) A revision of the nematode genus Meteterakis Karve, 1930. Parasitology 48: 9-31. https://doi.org/10.1017/ S003118200002103X

Junker K, Mariaux J, Measey GJ, Mutafchiev Y (2015) Meteterakis saotomensis n. sp. (Nematoda: Heterakidae) from Schistometopum thomense (Bocage) (Gymnophiona: Dermophiidae) on São Tomé Island. Systematic Parasitology 92: 131-139. https://doi.org/10.1007/s11230-015-9588-6

Karve JN (1930) Some parasitic nematodes of frogs and toads. Annals of Tropical Medicine and Parasitology 24: 481-491. https://doi.org/10.1 080/00034983.1930.11684653

Kreis HA (1933) Ein neuer parasitischer nematode aus Corucia zebrata (Scincidae; Reptilia). Ganguleterakis triaculeatus n. sp. Zeitschrift für Parasitenkunde 6: 332-338. https://doi.org/10.1007/BF02121952

Kurita K, Nakamura Y, Okamoto T, Lin S-M, Hikida T (2017) Taxonomic reassessment of two subspecies Chinese skink in Taiwan based on morphological and molecular investigations (Squamata, Scincidae). ZooKeys 687: 131-148. https://doi.org/10.3897/zookeys.687.12742
Naidu TS, Thakare VK (1981) On two nematodes from Fisher and Amphibians of Vidarbha region, Maharashtra state, India. Rivista di parassitologia 42: 415-424.

Norval G, Goldberg SR, Bursey CR, Mao J, Slater K (2014) Internal parasites of lizards from Taiwan. Herpetological Conservation and Biology 9: 484-494.

Oshmarin PG, Demshin NI (1972) The helminths of domestic and some wild animals in Viet Nam. Trudy Biologo-Pochyennogo Instuta Vladivostok 11: 5-115.

Okamoto T, Hikida T (2012) A new cryptic species allied to Plestiodon japonicus (Peters, 1864) (Squamata: Scincidae) from eastern Japan, and diagnoses of the new species and two parapatric congeners based on morphology and DNA barcode. Zootaxa 3436: 1-23.

Peters WCH (1864) Über die Eidechsenfamilie der Scincoiden, insbesonbere über die Schneider'schen, Wiegmann'schen unt neue Arten des zoologischen Museums. Monatsberichte der Königlichen Preuss Akademie der Wissenschaften zu Berlin 1864: 44-58.

Purwaningsih E, Dewi K, Hasegawa H (2015) Nematodes of amphibians from Java, Indonesia, with a description of new species, $\mathrm{Me}$ teterakis wonosoboensis n. sp. (Nematoda: Heterakoidea). Zootaxa 3974: 507-516. https://doi.org/10.11646/zootaxa.3974.4.3

Purwaningsih E, Dewi K, Nugroho HA (2016) Parasitic nematodes of amphibians from Lombok Island, Indonesia with description of Camallanus senaruensis sp. nov. and Meteterakis lombokensis sp. nov. Journal of Costal Life Medicine 4: 708-713. https://doi. org/10.12980/jclm.4.2016J6-181

Sandosham AA (1953) Malaysian parasite XV. Seven new worms from miscellaneous hosts. Studies from the Institute for Medical Research, Federation of Malaya 26: 212-226.

Sata N (2015) Distribution of parasitic nematodes in Japan with host-parasite relationship of lizards of Plestiodon (Reptilia: Squamata: Scincidae). Comparative Parasitology 82: 17-24. https://doi.org/10.1654/4728.1

Sata N (2018) Allopatric speciation of Meteterakis (Heterakoidea: Heterakidae), a highly dispersible parasitic nematode, in the East Asian islands. Parasitology International 67: 493-500. https://doi. org/10.1016/j.parint.2018.04.008

Soota TD Chaturvedi Y (1972) The helminth fauna of Andaman and Nicobar. Nematoda. Record of the Zoological Survey of India 66: 287-301.

Tanaka-Ueno Y, Matsui M, Chen S-L, Takenaka O, Ota H (1998) Phylogenetic relationships of brown frogs from Taiwan and Japan assessed by mitochondrial cytochrome $b$ gene sequences (Rana: Ranidae). Zoological Science 15: 283-288. https://doi.org/10.2108/zsj.15.283

Telford Jr SR (1997) The Ecology of a Symbiotic Community. Volume 1. Krieger Publishing Company, Malabar, $125 \mathrm{pp.}$

Thompson JC (1912) Herpetological Notics No. 2. Prodorome of Descriptions of New Species of Reptilia and Batrachia from the Far East. Privately published, San Francisco, 4 pp.

Wang PQ (1980) Studies on some new nematodes of the suborder Oxyirata from Fujian, China. Acta Zootaxonomica Sinica 5: 242-252.

Wilkie JS (1930) Some parasitic nematodes from Japanese Amphibia. Annals and Magazine of Natural History, Series 10(6): 606-614. https://doi.org/10.1080/00222933008673260

Yamaguti S (1935) Studies on the helminth fauna of Japan Part 10. Amphibian nematodes. Japanese Journal of Zoology 6: 387-392.

Yamaguti S (1941) Studies on the helminth fauna of Japan Part 34. Amphibian nematodes, II. Japanese Journal of Zoology 9: 397-409.

Zhang S, Zhang L (2011) A new species of Meteterakis Karve, 1930 (Nematoda: Heterakoide) form Indotestudo elongata (Blyth) in China with a key to the species of Meteterakis. Zootaxa 2869: 63-68. 